\title{
Impact of marital status on the prognosis of liver cancer patients without surgery and the critical window
}

\author{
Yuehui Liang $^{1}{ }^{\wedge}$, Xinyin $W^{1}{ }^{1}$, Chan Lu ${ }^{1,2}$, Fang Xiao ${ }^{1}$ \\ ${ }^{1}$ Xiangya School of Public Health, Central South University, Changsha, China; ${ }^{2}$ Hunan Engineering Research Center of Early Life Development \\ and Disease Prevention, Xiangya Hospital, Central South University, Changsha, China \\ Contributions: (I) Conception and design: F Xiao; (II) Administrative support: X Wu; (III) Provision of study materials or patients: C Lu; (IV) \\ Collection and assembly of data: Y Liang; (V) Data analysis and interpretation: Y Liang; (VI) Manuscript writing: All authors; (VII) Final approval of \\ manuscript: All authors. \\ Correspondence to: Fang Xiao. Xiangya School of Public Health, Central South University, No. 238 Shangmayuanling Road, Kaifu District, Changsha \\ 410078, China. Email: fangxiao@csu.edu.cn.
}

Background: Liver cancer (LC) is the second leading cause of cancer-associated mortality. However, the
critical time window during the marital status may influence the prognosis of LC is still unknown.
Methods: Information on a total of 4,933 patients diagnosed with primary LC who had not undergone
surgery was collected from the Surveillance, Epidemiology, and End Results (SEER) database to analyze
the impact of marital status on the risk of cancer-specific mortality (CSM). All confirmed patients were
monitored from January 1, 2010 until December 31, 2015 for the occurrence of death. We performed 1:1
propensity score matching among the married and non-married groups to eliminate dissimilarities in age,
sex, race and clinical characteristics. Cox proportional hazards regression model was adopted to investigate
the associations between marital status and the risk of CSM.

Results: Married patients were significantly negatively associated with the risk of CSM among patients compared to non-married status, with a hazard ratio (HR) [95\% confidence interval (CI)] of 1.15 (1.07-1.23). The strongest associations were observed for patients with Grade II, American Joint Committee on Cancer (AJCC) I and III. Furthermore, the protective effect of marriage on the prognosis of LC was independent of sex, age, race, grade, AJCC and SEER stage. Unmarried or separated patients may have a worse prognosis.

Conclusions: Marriage was strongly associated with a positive prognosis among patients with LC, especially in the critical window of Grade II, AJCC I and III. This study highlights the important impact of marriage on cancer prognosis.

Keywords: Liver cancer (LC); marriage; prognosis; social support; survival analysis

Submitted Sep 20, 2020. Accepted for publication Jan 14, 2021.

doi: 10.21037/apm-20-1885

View this article at: http://dx.doi.org/10.21037/apm-20-1885

\section{Introduction}

Liver cancer (LC) has posed a serious threat to human health because of its rapid growth, and strong invasiveness (1). According to cancer statistics, LC is the second leading cause of cancer-associated mortality and ranks as the fifth most common malignancy globally. It is estimated that approximately 850,000 new LC cases are diagnosed each year worldwide, and this number is still rising (2-4). In the United States, with approximately 41,000 new cases and 29,000 deaths from LC each year, LC

\footnotetext{
$\wedge$ ORCID: 0000-0002-2180-2235.
} 
is highly lethal, with mortality rising faster than any other cancer, and only about one-fifth of patients can survive for 5 years after diagnosis (5). High morbidity and mortality impose a severe disease burden on the nation (6). Therefore, exploring the prognostic factors affecting patients with liver cancer is important for effective reduction and early prevention of the development of LC.

Many studies have confirmed the prognostic factors of LC mainly regarding clinical characteristics, such as surgery, tumor size, pathological grade and American Joint Committee on Cancer (AJCC) stage (7). Although some studies have developed various prognostic evaluation models for patients with LC based on clinical information, the $\mathrm{C}$ index for evaluating the accuracy of these models can only explain approximately $80 \%(8,9)$. This suggests that other potential factors affecting the prognosis of LC patients have not received attention. Social determinants, despite being little addressed, play a role in the development of LC that cannot be overlooked. Recently, increasing evidence has indicated that social support can greatly affect the prognosis of many cancers, such as pancreatic neuroendocrine cancer (10), colorectal cancer (11) and breast cancer (12). Thus, it is necessary to investigate the effect of social support on LC.

Social support, referring to various forms of external support, has been reported to have beneficial effects on overall well-being (13). Family support, which can affect patients' choice of treatment and improve patients' compliance with treatment, is one of the most important social supports that closely related to the prognosis. Support from spouses is the most important family support for adults, and marital status has been considered an independent social factor that determines the prognosis of cancer patients. In the United States, only $50 \%$ of Americans are married (14), the rest being single, separated, unmarried, divorced and widowed. Most studies have mainly focused on the prognosis of married and unmarried patients, while those who are separated, divorced, and widowed have been ignored $(15,16)$. Some studies suggested that marriage as a prognostic factor showed both protective (17) and adverse (18) effects on the survival of cancer $(19,20)$, while others found no association between marriage and tumor prognosis (21). However, some studies addressed cancer patients who had undergone surgery, which makes it difficult to compare the role of marriage and surgery on the prognosis of LC. Given that some patients cannot undergo surgery, effective interventions via social support may be more meaningful for these patients to improve their prognosis in addition to limited treatments. Due to the inconclusive epidemiological findings, the role of marriage on the prognosis of LC patients without surgery warrants further investigation. In addition, the survival time of cancer patients in each clinical stage is distinctive, and the sensitivity of marital status on prognosis in each clinical stage is also different. Hence, the susceptible windows, being interpreted as a stronger association between marital status and risk of death, urgently need to be identified.

In this study, we conclude that marriage plays a role in the prognosis of LC for patients who have not undergone surgery. To test this hypothesis, we conducted the present study by using data from the Surveillance, Epidemiology, and End Results (SEER) to explore the relationship between marital status and outcomes of LC patients without surgery, and to further identify the relative importance of the susceptible window during the stages of cancer development.

We present the following article in accordance with the STROBE reporting checklist (available at http://dx.doi. org/10.21037/apm-20-1885).

\section{Methods}

\section{Patients characteristics}

The SEER program collects cancer morbidity, treatment, and survival data from population-based cancer registry organizations. The program involves approximately $97 \%$ of incident cancers, and the cancer registry organizations cover approximately $26 \%$ of the United States population, which has a high degree of recognition in the world (22). We searched the SEER database to identify 46,000 patients diagnosed between 2010 and 2015. The year 2010 was selected as the first year of the study given that the AJCC $7^{\text {th }}$ edition was introduced in SEER in 2010. The study was conducted in accordance with the Declaration of Helsinki (as revised in 2013). All the data are obtained from the public database, and there is no ethical approval.

The patient's elimination process is shown in Figure S1. We first excluded subjects with a diagnosed age $<18$ years and missing data with marital status and race. We then excluded subjects with missing data on the degree of tumor differentiation, tumor AJCC stage, and surgical status.

The variables in this study included demographic valuables (sex, age, race and marital status) and other valuables (pathological grade, AJCC and SEER stage). The endpoint of this study was liver cancer-specific mortality 
(CSM). Patients who survived the last follow-up were defaulted to censor. The survival time calculation started from the time of diagnosis, and the total survival time was defied as the period from diagnosis to death. All confirmed patients were monitored for the occurrence of death from January 1, 2010 until December 31, 2015.

Based on the incidence characteristics and sample distribution of LC, we then divided the patients into three groups of different ages: $\leq 60,60-75$, and $\geq 75$ years. The race included white, black, and other races.

The patients were subdivided into two groups: married and non-married (single, widowed, divorced, separated and unmarried). To exclude the heterogeneity of marital status and differences in baseline data, we performed 1:1 propensity score matching between the married and nonmarried groups.

\section{Statistical analysis}

Propensity score matching regarded marital status as a dependent variable, and each covariate (age, sex, race, grade, SEER stage and AJCC) was an independent variable. The propensity score value is estimated by logistic regression, and the 1:1 nearest neighbor matching method is used for matching. This process guarantees the matching result by defining the caliper value (caliper value $=0.02$ ), and then comparing the changes in the standard difference of covariates between groups before and after matching. When the absolute value of the standard difference is less than 0.1 $(10 \%)$, the balance of variables between groups is better.

First, we used the Chi-square test to compare the demographic and clinical characteristics of patients with different marital statuses. Second, we adopted the KaplanMeier curve analysis and the log-rank test to analyze the prognosis among patients with different marital statuses. Third, multivariate Cox regression model was utilized to estimate the effect of demographic and clinical factors on the hazard risk of prognosis for patients with LC. All statistical analyses were performed by the statistical software package SPSS for Windows, version 22 (IBM Corp., Armonk, NJ, USA). The associations in the regression analysis were estimated as hazard ratios (HRs) with $95 \%$ confidence intervals (95\% CIs). A P value $<0.05$ indicated statistical significance.

\section{Results}

We identified a total of 4,933 LC patients who had not undergone surgery between 2010 and 2015 from the SEER database. According to Table 1, 2,555 (51.7\%) patients were married, and 1,897 (50.0\%) patients were classified in various non-married states after matching. We observed that all demographics including sex, age and race were significantly associated with two different marital statuses $(\mathrm{P}<0.001)$. For the clinical characteristics, only significant differences in the AJCC stage were observed between different marital statuses. During the follow-up period, 2,060 patients died of LC in the non-married group. For the matched data set, the covariates were adequately balanced in the distribution of different marital statuses $(\mathrm{P}>0.05)$.

As displayed in Figure 1, the Kaplan-Meier survival analysis showed that the cancer-specific survival (CSS) rate of married patients was always higher than nonmarried group and the other marital status groups $(\mathrm{P}<0.05)$. When considering the matched data set, we found that the survival rate of the three groups was still different, and the median survival time of the married group was still longer than that of the single group after the log-rank test $(\mathrm{P}<0.05)$.

All of the above demographic and clinical variables were included in the Cox regression model. Marital status was associated with the CSM risk of LC patients. They were independent prognostic factors for LC patients without surgery, as shown in Table 2. Marital status had a significantly negative association with CSM risk. The nonmarried group had 9.3\% (HR, 1.09; 95\% CI, 1.03 to 1.16) risk increase in model I and 14\% (adjusted HR, 1.14; $95 \%$ $\mathrm{CI}, 1.07$ to 1.22 ) risk increase in CSM compared to the married group after performing a multivariable adjustment. In the matched data set, marriage also reduced the patient's risk of CSM to a greater degree (adjusted HR, 1.15; 95\% CI, 1.07 to 1.23 ).

As shown in Table 3, we used a multivariate Cox regression model to assess the impact of marital status on CSM among different clinical characteristic subgroups. The strongest protective effect was observed in the AJCC stage III (adjusted HR, 1.26; 95\% CI, 1.10 to 1.45 ). We found that marital status was a significant factor affecting the prognosis of patients who were grade II and AJCC stage I. In AJCC stage I, the CSM risk was 1.16 (adjusted HR, 1.16; 95\% CI, 1.02 to 1.32 ) times that of the non-married group. The results failed to reach significant differences in the risk of death among different marital statuses in other AJCC stages and pathological grades between the two marital status groups. 
Table 1 The distribution of marital status, in relation to baseline variables between the original and matched data sets

\begin{tabular}{|c|c|c|c|c|c|c|c|c|}
\hline Variables & \multicolumn{4}{|c|}{ Original data set } & \multicolumn{4}{|c|}{ Matched data set } \\
\hline Sample size, no. & 2,555 & 2,378 & & & 1,897 & 1,897 & & \\
\hline Age, years & & & -0.15 & 0.00 & & & 0.001 & 0.26 \\
\hline $18-60$ & 824 (32.3) & 955 (40.2) & & & 717 (37.8) & 730 (38.5) & & \\
\hline$\geq 75$ & 559 (21.9) & $440(18.5)$ & & & 328 (17.3) & $342(18.0)$ & & \\
\hline Sex & & & -0.23 & 0.00 & & & 0.013 & 0.50 \\
\hline Female & $403(15.8)$ & $612(25.7)$ & & & $378(19.9)$ & $367(19.3)$ & & \\
\hline Male & 2,152 (84.2) & $1,766(74.3)$ & & & $1,520(80.1)$ & $1,531(80.7)$ & & \\
\hline White & $1,798(70.4)$ & $1,606(67.5)$ & & & $1,420(74.8)$ & $1,369(72.1)$ & & \\
\hline Other & $491(19.2)$ & 238 (10.0) & & & $212(11.2)$ & $231(12.2)$ & & \\
\hline Grade & & & 0.005 & 0.53 & & & 0.003 & 0.31 \\
\hline 1 & $866(31.5)$ & 765 (32.2) & & & $612(32.2)$ & $610(32.1)$ & & \\
\hline II & $1,071(41.9)$ & $969(40.7)$ & & & 757 (39.9) & 767 (40.4) & & \\
\hline III & $631(24.7)$ & $589(24.8)$ & & & $490(25.8)$ & 472 (24.9) & & \\
\hline IV & $47(1.8)$ & $55(2.3)$ & & & $39(2.1)$ & $49(2.6)$ & & \\
\hline SEER stage & & & -0.05 & 0.14 & & & -0.008 & 0.26 \\
\hline II & $307(12.0)$ & $342(14.4)$ & & & $244(12.9)$ & $260(13.7)$ & & \\
\hline III & $674(26.4)$ & $571(24.0)$ & & & $477(25.1)$ & $458(24.1)$ & & \\
\hline IV & 797 (31.2) & $689(29.0)$ & & & $574(30.2)$ & $583(30.7)$ & & \\
\hline Death & 2,151 & 2,060 & & & 1,607 & 1,650 & & \\
\hline Survival month & $12.58 \pm 15.82$ & $11.30 \pm 14.26$ & & & $12.82 \pm 16.13$ & $11.08 \pm 14.24$ & & \\
\hline
\end{tabular}

Non-married include single, separated, unmarried, divorced and widowed. The matching factors included age, sex, race, pathological grade, AJCC and SEER stage. *, P value for $\chi^{2}$ test. ${ }^{\dagger}$, P value for McNemar's or McNemar-Bowker test. SEER, Surveillance, Epidemiology, and End Results; AJCC, American Joint Committee on Cancer.

Furthermore, to exclude the confounding caused by differences in patient baseline data and the heterogeneity of marital status, we redefined the single, separated/unmarried, divorced/widowed group. As displayed in Figure 2, the
Kaplan-Meier survival analysis showed that the CSS rate of married patients was higher than that of the other groups $(\mathrm{P}<0.05)$. After matching, the married group was still longer than that of the non-married group $(\mathrm{P}<0.05)$. 

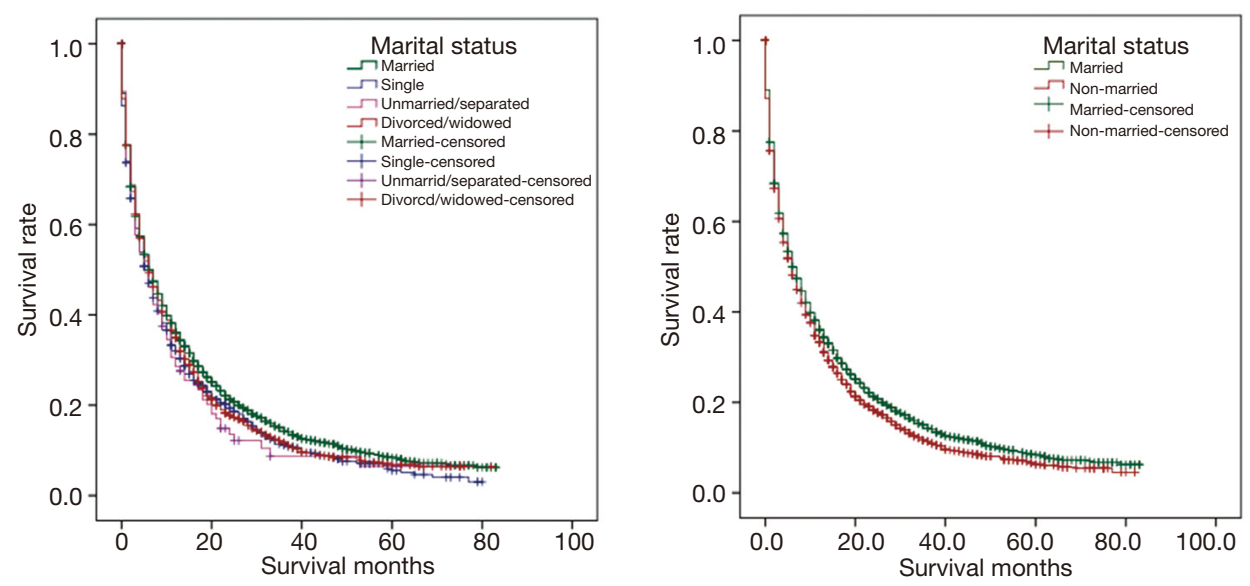

Figure 1 Kaplan-Meier survival curves demonstrating CSS rates of all patients according to marital status before matching. (A) CSS curves in LC patients without surgery among married and other groups $(\mathrm{n}=4,933), \mathrm{Chi}^{2}=10.41, \mathrm{P}=0.015$; (B) CSS curves in LC patients without surgery among married and non-married groups $(\mathrm{n}=4,933), \mathrm{Chi}^{2}=8.98, \mathrm{P}=0.003$. CSS, cancer-specific survival; $\mathrm{LC}$, liver cancer.

Table 2 The association between marital status and prognosis in original and matched data sets

\begin{tabular}{|c|c|c|c|}
\hline Variables & $\mathrm{HR}$ & $95 \% \mathrm{Cl}$ & $\mathrm{P}$ \\
\hline Married & 1.00 & & \\
\hline Non-married & 1.09 & $(1.03,1.16)$ & 0.004 \\
\hline \multicolumn{4}{|l|}{ Model II } \\
\hline Non-married & 1.14 & $(1.07,1.22)$ & 0.000 \\
\hline \multicolumn{4}{|l|}{ Model III } \\
\hline Married & 1.00 & & \\
\hline Non-married & 1.12 & $(1.05,1.20)$ & 0.001 \\
\hline Non-married & 1.15 & $(1.07,1.23)$ & 0.000 \\
\hline
\end{tabular}

Non-married include single, separated, unmarried, divorced and widowed. Model I did not adjust other variables before matching; Model II adjusted the variables include age, sex, race, grade, AJCC and SEER stage before matching; Model III did not adjust other variables after matching; Model IV adjusted the variables include age, sex, race, grade, AJCC and SEER stage after matching. HR, hazard ratio; Cl, confidence interval; AJCC, American Joint Committee on Cancer; SEER, Surveillance, Epidemiology, and End Results.

\section{Discussion}

To our knowledge, this study is one of the few studies to systematically investigate the impact of marriage on the risk of cancer death among LC patients who have not undergone surgery, and to further identify the critical window of the effect. Strikingly, we found that marriage had a significant protective effect on the risk of death among LC patients without surgery. We further observed that the AJCC III had relative importance of the impact in marriage in patients with LC. Moreover, we detected that marriage could decrease death risk of LC patients during Grade II and AJCC I stages. The survival rate of LC patients rapidly declined as the survival time increased, and the 
Table 3 Stratified analysis of marital status impact on prognosis among clinical characteristics after matching

\begin{tabular}{|c|c|c|c|c|}
\hline Variables & $\mathrm{HR}$ & $95 \% \mathrm{Cl}$ & $\mathrm{P}$ & $P_{\text {interaction }}$ \\
\hline \multicolumn{5}{|l|}{ Grade I } \\
\hline Married & 1.00 & & & \\
\hline Non-married & 1.10 & $(0.97,1.25)$ & 0.142 & \\
\hline Married & 1.00 & & & \\
\hline Non-married & 1.21 & $(1.08,1.35)$ & 0.001 & \\
\hline \multicolumn{5}{|l|}{ Grade III } \\
\hline Married & 1.00 & & & \\
\hline Married & 1.00 & & & \\
\hline Non-married & 1.00 & $(0.63,1.60)$ & 0.995 & \\
\hline Model b & & & & 0.000 \\
\hline \multicolumn{5}{|l|}{ AJCC I } \\
\hline Married & 1.00 & & & \\
\hline Non-married & 1.16 & $(1.02,1.32)$ & 0.024 & \\
\hline \multicolumn{5}{|l|}{ AJCC II } \\
\hline Married & 1.00 & & & \\
\hline Married & 1.00 & & & \\
\hline Non-married & 1.06 & $(0.94,1.19)$ & 0.327 & \\
\hline
\end{tabular}

Model a adjusted the variables include age, sex, race, AJCC and SEER stage after matching; Model b adjusted the variables include age, sex, race, grade and SEER stage after matching. HR, hazard ratio; $\mathrm{Cl}$, confidence interval; AJCC, American Joint Committee on Cancer; SEER, Surveillance, Epidemiology, and End Results.

decreasing rate remained steady 40 months after diagnosis. Our findings have significant implications for the effective control and early prevention of LC development.

The present study has several strengths. First, this is one of the few studies to systematically examine the impact of marital status on the prognosis of LC patients without surgery. Second, we collected a relatively large sample size of patients with LC, which can, to a large extent, ensure the accuracy and reliability of our results. Third, our findings may provide an effective strategy for public health and cancer control especially in sensitive populations.

We found a protective effect of marriage on the death risk of LC among patients without surgery. Subsequently, we compared the benefits of various treatments on the prognosis of LC through a literature review in Table S1 with marriage in this study. The benefit of patients 

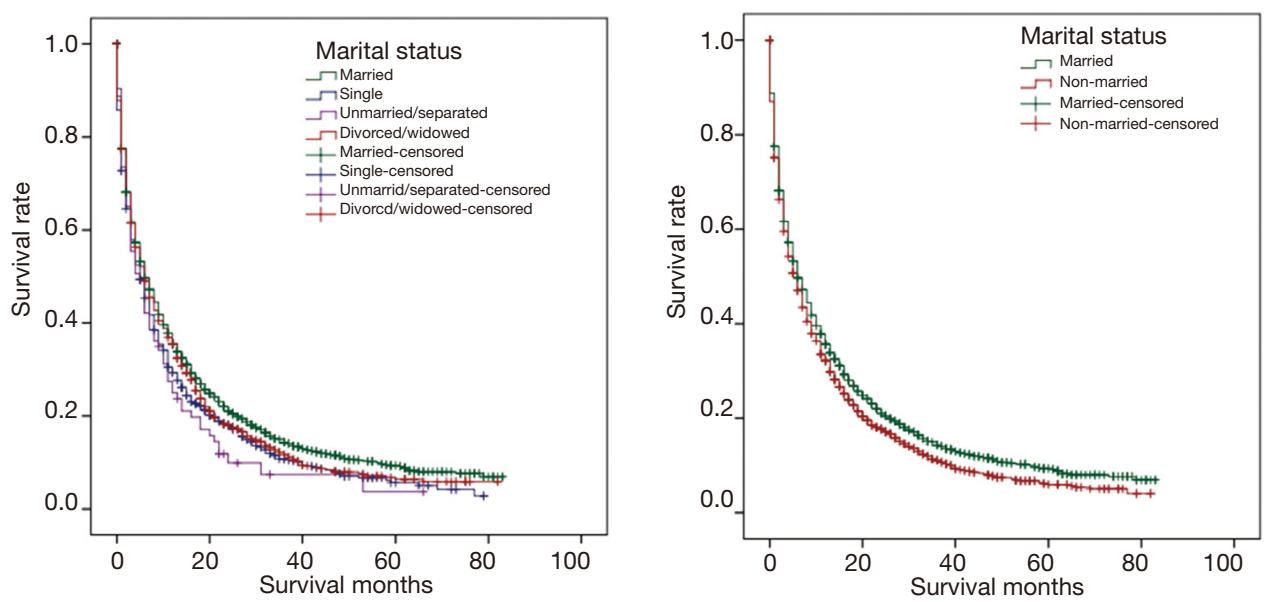

Figure 2 Kaplan-Meier survival curves demonstrating CSS rates of all patients according to marital status after matching. (A) CSS curves in LC patients without surgery among married and other groups ( $\mathrm{n}=3,794), \mathrm{Chi}^{2}=15.78, \mathrm{P}=0.001$; (B) CSS curves in LC patients without surgery among married and non-married groups $(\mathrm{n}=3,794), \mathrm{Chi}^{2}=11.34, \mathrm{P}=0.001$. CSS, cancer-specific survival; LC, liver cancer.

receiving single-drug chemotherapy was very low compared to the benefits of marriage, and marital patients possessed a "nontherapeutic" benefit. This study was also a vigorous manifestation of the "biological-psychological-social" medical model, suggesting that we must pay attention to both physiological and psychosocial factors in the prevention and treatment of cancer $(23,24)$. Social support is considered to be the individual's support from the outside world through various means, including material and spiritual guarantees, and directly promotes the physical and mental health of the individual (25). Previous studies have shown that lower social support is associated with a poorer prognosis for cancer patients (12). We found that marriage, one of the most important social supports, was associated with the positive prognosis of LC patients. How did marriage exert its role on the prognosis of cancer patients? Some studies revealed that the better prognosis of married cancer patients could partly be attributed to earlier diagnosis (26). Our results also showed that married patients in AJCC I were the highest proportion compared with the other two groups, indicating that married patients might tend to receive a diagnosis at an earlier stage. An additional explanation might be related to the spouse's recommendation to go for a health checkup once the problem was discovered (27). Therefore, patients went to the hospital earlier and received treatment in the earlier stage of the disease. Moreover, spouses could also prompt patients to follow health-related behaviors, directly or indirectly. Reblin et al. suggested that a shared social environment created in marriage could be important to motivate cancer patients to engage in healthy behaviors (28). Another reason might be to that patients could receive high-quality care from their spouse at home. Galbraith et al. found that more than $50 \%$ of prostate cancer patients' health-related outcome scores were related to spouses, which would be beneficial for the health of patients if their spouses participated in nursing (29).

We identified that the protective effect of marriage on the prognosis of LC was significantly stronger in critical time windows during pathological grades and AJCC stage. The CSM risk significantly decreased in married patients compared with other groups, which indicated that AJCC III may act as a critical time window for the strongest protective effect of marriage. We also found that married LC patients had a lower risk of death in Grade II and AJCC I stages than those non-married patients. Very few works have examined the protective effect of marriage in specific pathological grades or AJCC stages. Li et al. demonstrated that marriage has protective effects on patients with colorectal cancer in the AJCC (II, III and IV) based on all populations (30). Another study on hepatocellular carcinoma found that married patients had the lowest risk of death when the tumor was in the localized or regional (tumor has no metastasis) stage (31). Although the patient origins of these studies were different, the conclusions were consistent with our results. We drew the above conclusions by performing 1:1 propensity score matching between the marriage group and the non-marriage group 
to eliminate the heterogeneity of various marital statuses and the differences in baseline data. The conclusions were consistent with previous results. It has become clear that marriage was negatively associated with the risk of LC death in the regional stage or moderately differentiated grade, suggesting that some genetic biomarkers are involved in the process of susceptibility (32). The association between marriage and survival in a specific period indicated an underlying biologically plausible explanation. Marriage was an important part of people's lives. It provided a haven to alleviate the mental and physical damage of individuals in response to stressful events. Hepatocellular carcinoma cells in Grade II were moderately differentiated and their malignancy was between Grade I and III. Adequate mental support could activate the immune system to eliminate malignant cancer cells and induce tumors to transform into lower grades (33). However, the biological mechanism by which marriage reduced the risk of death for patients in this period is still unknown and deserves further study.

Our study has several limitations worth noting. First, the SEER database did not include changes in the patient's marital status. The marital status of the study was recorded at the time of diagnosis. Only the marital status at the baseline level of each patient was analyzed. The relationship between marital status transition and disease prognosis was not studied. Second, married patients also have many different characteristics, such as the length of marriage and the happiness of the marriage. An unhappy marriage may have an adverse influence (34). Economic status is another recognized independent prognostic factor of LC (35). Third, the database did not provide relevant data. Additionally, the SEER database only provided surgical information and did not provide information on patients with radiotherapy, chemotherapy, palliative care, and immunotherapy. Other potential factors that could affect the prognosis of LC were not included in the multivariate analysis of this study.

Our study found a significant association between marital status and the overall mortality and CSM of LC patients without surgery. We further identified that this protective effect had relative importance during the AJCC III staging system. Marriage also exerted an important role in the decreased death risk of patients who live cancer in AJCC I and Grade II. Strikingly, marriage could greatly increase the survival rate of patients with LC. According to our analysis, we suggest that some effective strategies such as social support should be taken into account for cancer populations for early control and prevention. For single cancer patients, it is better to benefit from marriage to improve their prognosis in addition to clinical treatments.

\section{Conclusions}

Marriage is an independent factor that could significantly decrease the risk of death attributed to LC.

\section{Acknowledgments}

The authors would like to thank the Surveillance, Epidemiology, and End Results (SEER) database for the support.

Funding: The current work was supported by National Natural Science Foundation of China (No. 81773478).

\section{Footnote}

Reporting Checklist: The authors have completed the STROBE reporting checklist. Available at http://dx.doi. org/10.21037/apm-20-1885

Conflicts of Interest: All authors have completed the ICMJE uniform disclosure form (available at http://dx.doi. org/10.21037/apm-20-1885). The authors have no conflicts of interest to declare.

Ethical Statement: The authors are accountable for all aspects of the work in ensuring that questions related to the accuracy or integrity of any part of the work are appropriately investigated and resolved. The study was conducted in accordance with the Declaration of Helsinki (as revised in 2013). All the data are obtained from the public database, and there is no ethical approval.

Open Access Statement: This is an Open Access article distributed in accordance with the Creative Commons Attribution-NonCommercial-NoDerivs 4.0 International License (CC BY-NC-ND 4.0), which permits the noncommercial replication and distribution of the article with the strict proviso that no changes or edits are made and the original work is properly cited (including links to both the formal publication through the relevant DOI and the license). See: https://creativecommons.org/licenses/by-nc-nd/4.0/.

\section{References}

1. Forner A, Reig M, Bruix J. Hepatocellular carcinoma. 
Lancet 2018;391:1301-14.

2. Ferlay J, Colombet M, Soerjomataram I, et al. Estimating the global cancer incidence and mortality in 2018: GLOBOCAN sources and methods. Int J Cancer 2019; 144:1941-53.

3. Bray F, Ferlay J, Soerjomataram I, et al. Global cancer statistics 2018: GLOBOCAN estimates of incidence and mortality worldwide for 36 cancers in 185 countries. CA Cancer J Clin 2018;68:394-424.

4. Wilson JF. Liver cancer on the rise. Ann Intern Med 2005;142:1029-32.

5. Islami F, Miller KD, Siegel RL, et al. Disparities in liver cancer occurrence in the United States by race/ethnicity and state. CA Cancer J Clin 2017;67:273-89.

6. Akinyemiju T, Abera S, Ahmed M, et al. The burden of primary liver cancer and underlying etiologies from 1990 to 2015 at the global, regional, and national level: results from the global burden of disease study 2015. JAMA Oncol 2017;3:1683-91.

7. Bruix J, Reig M, Sherman M. Evidence-based diagnosis, staging, and treatment of patients with hepatocellular carcinoma. Gastroenterology 2016;150:835-53.

8. Farinati F, Vitale A, Spolverato G, et al. Development and validation of a new prognostic system for patients with hepatocellular carcinoma. PLoS Med 2016;13:e1002006.

9. Suk KT, Kim EJ, Kim DJ, et al. Prognostic significance of hemodynamic and clinical stages in the prediction of hepatocellular carcinoma. J Clin Gastroenterol 2017;51:285-93.

10. Zhou H, Zhang Y, Song Y, et al. Marital status is an independent prognostic factor for pancreatic neuroendocrine tumors patients: an analysis of the Surveillance, Epidemiology, and End Results (SEER) database. Clin Res Hepatol Gastroenterol 2017;41:476-86.

11. Sarma EA, Kawachi I, Poole EM, et al. Social integration and survival after diagnosis of colorectal cancer. Cancer 2018;124:833-40.

12. Thompson T, Rodebaugh TL, Perez M, et al. Influence of neighborhood-level factors on social support in earlystage breast cancer patients and controls. Soc Sci Med 2016;156:55-63.

13. Applebaum AJ, Stein EM, Lord-Bessen J, et al. Optimism, social support, and mental health outcomes in patients with advanced cancer. Psychooncology 2014;23:299-306.

14. Aizer AA, Chen MH, Mccarthy EP, et al. Marital status and survival in patients with cancer. J Clin Oncol 2013;31:3869-76.

15. Wu C, Chen P, Qian JJ, et al. Effect of marital status on the survival of patients with hepatocellular carcinoma treated with surgical resection: an analysis of 13,408 patients in the Surveillance, Epidemiology, and End Results (SEER) database. Oncotarget 2016;7:79442-52.

16. Gore J L, Kwan L, Saigal CS, et al. Marriage and mortality in bladder carcinoma. Cancer 2005;104:1188-94.

17. Osborne C, Ostir GV, Du X, et al. The influence of marital status on the stage at diagnosis, treatment, and survival of older women with breast cancer. Breast Cancer Res Treat 2005;93:41-7.

18. Hinyard L, Wirth LS, Clancy JM, et al. The effect of marital status on breast cancer-related outcomes in women under 65: a SEER database analysis. Breast 2017;32:13-7.

19. Fosså SD, Cvancarova M, Chen L, et al. Adverse prognostic factors for testicular cancer-specific survival: a population-based study of 27,948 patients. J Clin Oncol 2011;29:963-70.

20. Mahdi H, Kumar S, Munkarah AR, et al. Prognostic impact of marital status on survival of women with epithelial ovarian cancer. Psychooncology 2013;22:83-8.

21. Jatoi A, Novotny P, Cassivi S, et al. Does marital status impact survival and quality of life in patients with nonsmall cell lung cancer? Observations from the mayo clinic lung cancer cohort. Oncologist 2007;12:1456-63.

22. Boffa DJ, Rosen JE, Mallin K, et al. Using the national cancer database for outcomes research: a review. JAMA Oncol 2017;3:1722-8.

23. Zucchetti G, Bellini S, Bertolotti M, et al. The biopsychosocial condition of childhood cancer survivors in the transition towards adult care: a national survey from the joint pediatric and adult transition care group. Int J Adolesc Med Health 2018. [Epub ahead of print]. doi: 10.1515/ijamh-2018-0189.

24. Fabi A, Falcicchio C, Giannarelli D, et al. The course of cancer related fatigue up to ten years in early breast cancer patients: what impact in clinical practice? Breast 2017;34:44-52.

25. Kelly ME, Duff H, Kelly S, et al. The impact of social activities, social networks, social support and social relationships on the cognitive functioning of healthy older adults: a systematic review. Syst Rev 2017;6:259.

26. Syse A, Lyngstad TH. In sickness and in health: the role of marital partners in cancer survival. SSM Popul Health 2016;3:99-110.

27. Saghari S, Ghamsary M, Marie-Mitchell A, et al. Sociodemographic predictors of delayed- versus earlystage cervical cancer in California. Ann Epidemiol 2015;25:250-5. 
28. Reblin M, Birmingham WC, Kohlmann W, et al. Support and negation of colorectal cancer risk prevention behaviors: analysis of spousal discussions. Psychol Health Med 2018;23:548-54.

29. Galbraith ME, Pedro LW, Jaffe AR, et al. Describing health-related outcomes for couples experiencing prostate cancer: differences and similarities. Oncol Nurs Forum 2008;35:794-801.

30. Li Q, Gan L, Liang L, et al. The influence of marital status on stage at diagnosis and survival of patients with colorectal cancer. Oncotarget 2015;6:7339-47.

31. Zhang W, Wang $X$, Huang $R$, et al. Prognostic value of marital status on stage at diagnosis in hepatocellular carcinoma. Sci Rep 2017;7:41695.

32. Dinan MA, Mi X, Reed SD, et al. Initial trends in the use of the 21-gene recurrence score assay for patients with breast cancer in the medicare population, 2005-2009. JAMA Oncol 2015;1:158-66.

33. Pregnolato M, Damiani G, Pereira A Jr. Patterns of calcium signaling: a link between chronic emotions and cancer. J Integr Neurosci 2017;16:S43-63.

34. Fox CM, Harper AP, Hyner GC, et al. Loneliness, emotional repression, marital quality, and major life events in women who develop breast cancer. J Community Health 1994;19:467-82.

35. Wang CC, Tsai MC, Peng CM, et al. Favorable liver cancer mortality-to-incidence ratios of countries with high health expenditure. Eur J Gastroenterol Hepatol 2017;29:1397-401.
Cite this article as: Liang $\mathrm{Y}, \mathrm{Wu} \mathrm{X}, \mathrm{Lu} \mathrm{C}$, Xiao F. Impact of marital status on the prognosis of liver cancer patients without surgery and the critical window. Ann Palliat Med 2021;10(3):29902999. doi: 10.21037/apm-20-1885 
Table S1 Comparison of HR for different endpoint associated with treatment reported in the literature with marriage in LC patients

\begin{tabular}{|c|c|c|c|c|c|}
\hline Author, year & Study type & Reference & Treatment & Study population & Adjusted HR (95\% Cl) \\
\hline $\begin{array}{l}\text { Llovet et al., } \\
2002(36)\end{array}$ & Randomized controlled trial & $\begin{array}{l}\text { Conservative } \\
\text { treatment }\end{array}$ & $\begin{array}{l}\text { Chemoembolisation (gelatin } \\
\text { sponge, doxorubicin) }\end{array}$ & Child-Pugh class A or $B, n=112$ & Overall mortality: 0.47 (0.25-0.91) \\
\hline $\begin{array}{l}\text { Bai et al., } \\
2013(37)\end{array}$ & $\begin{array}{l}\text { Prospective non- randomized } \\
\text { controlled trial }\end{array}$ & TACE & Sorafenib plus TACE & $\begin{array}{l}\text { Unresectable intermediate or advanced } \\
\mathrm{HCC}, \mathrm{n}=304\end{array}$ & $\begin{array}{l}\text { Time-to-progression: } 0.60(0.42-0.85) \text {; } \\
\text { median survival time: } 0.61(0.42-0.88)\end{array}$ \\
\hline $\begin{array}{l}\text { Bruix et al., } \\
2017 \text { (38) }\end{array}$ & $\begin{array}{l}\text { Randomised, double-blind, } \\
\text { parallel-group, phase } 3 \text { trial }\end{array}$ & Placebo & Regorafenib & Advanced HCC, $n=843$ & Overall survival: 0.63 (0.50-0.79) \\
\hline $\begin{array}{l}\text { Cheng et al., } \\
2009 \text { (39) }\end{array}$ & $\begin{array}{l}\text { Multinational phase III, randomised, } \\
\text { double-blind, placebo-controlled trial }\end{array}$ & Placebo & Sorafenib & $\begin{array}{l}\text { Unresectable or metastatic hepatocellular } \\
\text { carcinoma, } n=304\end{array}$ & $\begin{array}{l}\text { Median survival time: } 0.68(0.50-0.93) \text {; } \\
\text { median time to progression: } 0.57(0.42-0.79)\end{array}$ \\
\hline $\begin{array}{l}\text { Kudo et al., } \\
2018 \text { (40) }\end{array}$ & $\begin{array}{l}\text { Open-label, randomised, } \\
\text { phase } 3 \text { trial }\end{array}$ & Sorafenib & $\begin{array}{l}\text { Sorafenib plus hepatic } \\
\text { arterial infusion chemotherapy }\end{array}$ & $\begin{array}{l}\text { Advanced and not suitable for resection, } \\
\text { local ablation, or transarterial } \\
\text { chemoembolization, } n=205\end{array}$ & Median survival time: $1.01(0.74-1.37)$ \\
\hline $\begin{array}{l}\text { Pinter et al., } \\
2015 \text { (41) }\end{array}$ & $\begin{array}{l}\text { Randomized controlled trial, } \\
\text { double-blind }\end{array}$ & $\begin{array}{l}\text { TACE plus } \\
\text { placebo }\end{array}$ & TACE plus doxorubicin & Early or intermediate HCC, $n=40$ & Median survival time: $1.70(0.80-3.60)$ \\
\hline- & This study & Married & Non-married & AJCC III HCC, $n=3,794$ & CSM: 1.26 (1.10-1.45) \\
\hline
\end{tabular}

HR, hazard ratio; LC, liver cancer; Cl, confidence interval; TACE, transcatheter arterial chemoembolization; BCLC, Barcelona clinic liver cancer; CSM, cancer-specific mortality.

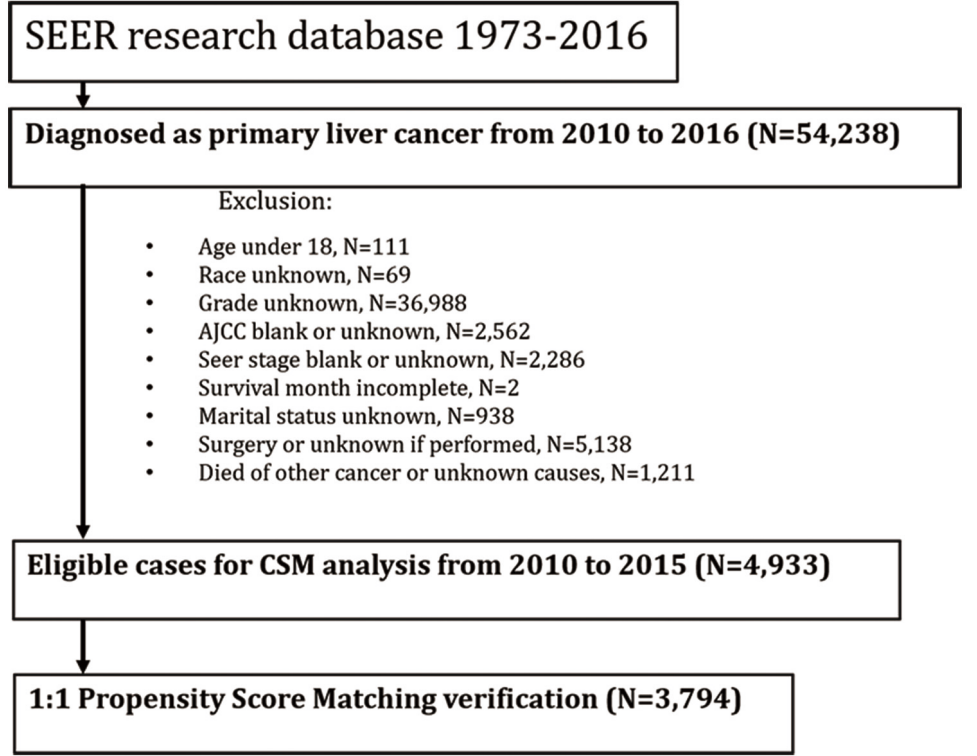

Figure S1 Flowchart of the enrolled patients in the study. SEER, Surveillance, Epidemiology, and End Results; CSM, cancer-specific mortality.

\section{References}

36. Llovet JM, Real MI, Montana X, et al. Arterial embolisation or chemoembolisation versus symptomatic treatment in patients with unresectable hepatocellular carcinoma: a randomised controlled trial. Lancet 2002;359:1734-9.

37. Bai W, Wang YJ, Zhao Y, et al. Sorafenib in combination with transarterial chemoembolization improves the survival of patients with unresectable hepatocellular carcinoma: a propensity score matching study. J Dig Dis 2013;14:181-90.

38. Bruix J, Qin S, Merle P, et al. Regorafenib for patients with hepatocellular carcinoma who progressed on sorafenib treatment (RESORCE): a randomised, double-blind, placebo-controlled, phase 3 trial. Lancet 2017;389:56-66.

39. Cheng AL, Kang YK, Chen Z, et al. Efficacy and safety of sorafenib in patients in the Asia-Pacific region with advanced hepatocellular carcinoma: a phase III randomised, double-blind, placebo-controlled trial. Lancet Oncol 2009;10:25-34.

40. Kudo M, Ueshima K, Yokosuka O, et al. Sorafenib plus low-dose cisplatin and fluorouracil hepatic arterial infusion chemotherapy versus sorafenib alone in patients with advanced hepatocellular carcinoma (SILIUS): a randomised, open label, phase 3 trial. Lancet Gastroenterol Hepatol 2018;3:424-32.

41. Pinter M, Ulbrich G, Sieghart W, et al. Hepatocellular carcinoma: a phase II randomized controlled double-blind trial of transarterial chemoembolization in combination with biweekly intravenous administration of bevacizumab ora placebo. Radiology 2015;277:903-12. 